\title{
Experiencia y memoria en Los anillos de Saturno de W.G. Sebald: la ética/política del arte narrativo sebaldiano
}

Belisario Zalazar

Universidad Nacional de Córdoba - Argentina

\begin{abstract}
Resumo
Neste trabalho propomos refazer os caminhos da memória definida pelo narrador de Os anéis de Saturno, cujo trabalho árduo e doloroso envolve o negativo da fotografia da história do próprio progresso do relato da Modernidade, revelando o desastre e a destruição perpetrados pelo chamado processo de modernização capitalista. A narrativa sebaldiana neste ponto coincide com o projeto filosófico de Walter Benjamin, conforme descrito em suas teses "Sobre o conceito de história".
\end{abstract}

Palavras-chave: Memória; História; Modernidade; Catástrofes.

\section{Resumen}

En el siguiente trabajo proponemos desandar los caminos de la memoria trazados por el narrador de Los anillos de Saturno, cuyo arduo y doloroso trabajo supone el negativo de la fotografía de la historia del progreso propio del relato de la Modernidad, develando las catástrofes y la destrucción perpetradas por el llamado proceso de modernización capitalista. La narración sebaldiana coincide en este punto con el proyecto del filósofo Walter Benjamin esbozado en textos como sus tesis "Sobre el concepto de historia".

Palabras clave: Memoria; Historia; Modernidad; Catástrofes. 


\section{Narrar la experiencia: el trabajo de la memoria}

1. CADAVA, Eduardo. Trazos de luz: Tesis sobre la fotografía de la historia, 2014, p. 21.

2. WEBER, Samuel.

"Experiencia", 2014, p. 489.

3. Estas reflexiones, entre ellas la demarcación entre experiencia $\mathrm{y}$ vivencia, son deudoras del ensayo de Weber en su entrada al concepto de "Experiencia" sobre los conceptos de Walter Benjamin.

4. Desde una perspectiva evolucionista se sostiene que la memoria de un organismo vivo puede dividirse en dos categorías: una filogenética, la cual almacena información referida a la especie de la que el organismo/individuo forma parte, y la cual se transmite genéticamente (sobre todo comportamientos, o rasgos adquiridos), y otra ontogenética, la cual corresponde al aprendizaje y el contenido de lo vivido por el individuo desde su formación intrauterina, pasando por el nacimiento, el desarrollo, hasta llegar a su muerte.

5. WEBER, Samuel.

"Experiencia", 2014, p. 490-491.

6. SEBALD, W.G. Los anillos de Saturno, 2002.
El nudo problemático de la experiencia como concepto socio-histórico y, por lo tanto, el de su sentenciada destrucción, empobrecimiento o imposibilidad en determinadas condiciones materiales de existencia, debe ser puesto en relación con la cuestión del "pensamiento como memoria y la dimensión técnica del memorizar -las técnicas de inscripción material"1. Pues si la experiencia, en cuanto dimensión de la praxis humana a partir de la cual se obtiene una imagen de la relación articulatoria con uno mismo y con el mundo, "está ligada a las relaciones del trabajo, de la comunicación y del recuerdo"2 como pensaba Benjamin, lo decisivo estriba en las potencias y obstáculos del trabajo de la memoria. La memoria equivale aquí no sólo al reducto psíquico del recuerdo individual, sino que la praxis del recuerdo que construye la experiencia, tiene implicancias en la imagen que una sociedad posee de sí y de su historia.

Aquello con lo que trabaja la memoria para producir experiencias es la vivencia, el material de lo vivido por un sujeto o conjunto de sujetos. Pero si la posibilidad de tener experiencia se halla cercenada en unas condiciones sociales dadas (el capitalismo tardío en tiempos de la globalización), esto se debe, entre otros factores, a la elevación de la vivencia al rango de categoría articulatoria del sí mismo con el mundo ${ }^{3}$. Con la valoración de la vivencia en tanto bien preciado, a través de la socialización mediada por las mercancías (la espectacularizaicón del mundo que oferta un consumo ilimitado, consumo que conduce al placer inmediato y al deseo insatisfecho para de nuevo volver al origen del círculo estático, imaginado como progresivo), la memoria pierde sus potenciales ontogenéticos y se reduce en cierto punto su riqueza filogenética, reservorio biológico adquirido a lo largo de la historia de la especie ${ }^{4}$. Y con ella lo que fracasa o entra en crisis es la experiencia, como "apropiación elaboradora de vivencias" y "actividad (...) que debe posibilitar la autotransformación como transformación del mundo"s.

El problema de la memoria y su relación con la escritura de la historia (un modo particular de entender esa escritura que a su vez devuelve una concepción determinada de lo que pueda ser la historia) podríamos decir que funda, en tanto cimiento y simiente, el proyecto literario sebaldiano, y cruza toda la narración de Los anillos de Saturno ${ }^{6}$, obra de la que parte nuestro análisis. En sus ensayos, narraciones, y el largo poema en prosa Del natural, el autor alemán radicado en Norfolk (Inglaterra) emprendió una tarea sostenida en una serie de preocupaciones, cuya puesta en escritura puede ser pensada como una terapéutica 
para conjurar esos fantasmas que insistentemente volvían sobre su espíritu melancólico. En Los anillos de Saturno ${ }^{7}$, el tópico de la memoria es el punto de clivaje donde se trenzan los nudos de la historia de la Modernidad y las sombras de la destrucción que el historicismo positivista ocultó en aras de una idea iluminista de la Historia.

Pues, en una de sus múltiples dimensiones, la extensa narración que se compone de incontables historias hechas de recuerdos personales, de escrituras de muchos otros, de testimonios ajenos, de sueños propios e impropios, de fotografías y reflexiones varias, es, en definitiva, una historia de los claroscuros de la modernidad. Una historia de las tantas posibles, cercana quizás al esfuerzo emprendido por Walter Benjamin (presencia espectral en la obra de Sebald ${ }^{8}$ ), quien, según Eduardo Cadava, buscó con su inmensa obra filosófica, literaria y ensayística llevar a cabo una deconstrucción de la historia de la modernidad 9 . Y la historia de la Modernidad se desenvuelve, para ambos pensadores, como efecto de la ideología y del discurso del progreso. Como afirma Gerciano Maciel Pereira:

Ao contrário do anjo da tese IX, de Walter Benjamin, Sebald consegue se desvencilhar do sopro que vem do paraíso, e voltar para juntar os cacos da história, e tirar dos escombros os mortos, que com suas histórias e memórias revelam o lado obscuro da evolução racionalista da humanidade. ${ }^{10}$

Desde una perspectiva teórica, la experiencia circula por los vasos sanguíneos del entramado social, desde donde da lugar a la tradición, siendo la traducibilidad de una vivencia trabajada en el recuerdo el motor que pone en marcha el proceso vital de los individuos en sociedad. Cuando la memoria se obtura, ya sea debido a que se delega total o parcialmente a dispositivos técnicos, o porque es entregada a las fauces del olvido (por concebirla un peso que retarda la vivencia exultante del presente en su aspiración al futuro en inminente fuga), los lazos entre deseo y experiencia se rompen, y los hombres pierden espesor existencial. La pérdida de este espesor que mancomuna tiempos y espacios múltiples, tensionando el presente con el pasado para hacerse un espaciamiento hacia el porvenir, corresponde a la crisis de la experiencia genuina percibida por Benjamin. Como apunta Weber leyendo al berlinés:

El "orden de la experiencia" es dinámico y Benjamin establece el "deseo" como una de los elementos de esa dinámica. El deseo anticipa el tiempo, la experiencia lo estructura. Si la experiencia es pasado presente, el deseo es futuro presente en tanto energía pasional. Entre lo saciado de la
7. Del mismo modo que sucede en Sobre la bistoria natural de la destrucción, ensayo que en una decisión hermenéutica planteamos como un apéndice del Capitulo Segundo de la obra en cuestión.

8. Espectral ya que pocas veces se hace efectivamente presente, mas no por eso nunca deja de estar allí, alimentando sus reflexiones sobre la visión de la historia, y su materialismo a la hora de escribir sobre ella, o bien compartiendo su carácter melancólico. Lo cita explícitamente una sola vez en Sobre bistoria natural de la destrucción (SEBALD, W.G. 2003, p. 76), más precisamente su Tesis IX en la cual introduce a partir del cuadro de Klee, la reflexión sobre el ángel de la historia. Por otra parte, en su texto-homenaje a Walser, lo nombra como un comentarista audaz de la obra del escritor suizo. (Cf. SEBALD, W.G. Elpaseante solitario. En recuerdo a Robert Walser, 2008, p. 36). En un par de ensayos de Campo santo se hace más evidente la lectura de los textos benjaminianos (Cf. SEBALD, W.G. Campo Santo, 2007, p. 78, 101, 111). Nuestra lectura de Sebald piensa a Benjamin como una de sus tantas afinidades electivas, a la par de Walser, de Thomas Browne o de Michel Hamburger. Ben Hutchinson da al respecto datos precisos sobre la presencia benjaminiana, en este caso en la biblioteca personal de Sebald: "Na parte da biblioteca de Sebald que é mantida no Deutsches Literaturarchiv em Marbach am Neckar, encontramse quatorze livros de ou sobre Benjamin.” (HUTCHINSON, Ben, "Marinheiro ou camponês? Algumas reflexões sobre as leituras de Sebald do ensaio ' $O$ narrador' de Walter Benjamin", 2016, p. 87).

9. Cf. CADAVA, Eduardo. Trazos de lur. Tesis sobre la fotografía de la bistoria, 2014.

10. MACIEL PEREIRA, Gerciano. "Algumas Reflexões sobre W.G. Sebald à luz de Walter Benjamin”, 2011, p. 71. 
11. WEBER, Samuel.

"Experiencia", 2014, p. 505.

12. Cf. AGAMBEN Giorgio.

Estancias. La palabra y el fantasma en la cultura occidental, 2014. experiencia y lo incumplido del deseo existe una conexión que mantiene en marcha el proceso vital. (...) En el "orden de la vivencia", en cambio, en el que ya no se puede hacer "demasiadas cosas con la experiencia", el deseo es reprimido por la "avidez", en tanto contracara del "afán de lucro" de la sociedad de consumo. ${ }^{11}$

\section{Cita secreta con las generaciones vencidas del pasado: la lucha de la memoria contra el olvido}

El individuo, al rememorar la vivencia y trabajarla en el tiempo, actualiza su estancia en el mundo, restituyendo una relación consigo y con el entorno que va más allá de la inmediatez de la presencia sensible de las cosas. En ese lapso espacio-temporal, el hombre se abre a una relación con los seres que sortea las estaciones del goce del valor de uso y de la acumulación del valor de cambio ${ }^{12}$. Una puerta que lleva hacia la restitución de la experiencia y de la memoria en tanto categorías ponderadas para imaginar otro modo de habitar la Tierra, ya que con ellas rememoramos (actualizándolo) un habitar que, según algunos autores como Benjamin, tiene en la infancia un referente. La infancia emerge en los textos del berlinés o de Agamben, quien recupera muchas de sus ideas, en tanto universo espiritual, y no ya como una supuesta etapa subjetiva superada por procesos de socialización. En la figura del juguetefetiche, antaño indistinguibles de objetos que tenían la mayoría de las veces significado religioso, Agamben encuentra el lugar que señala otra imagen de la experiencia humana como ser-enel-mundo, o ser-en-esferas. Esta es una imagen que niega las cartografías dibujadas con tinta epistemológica, fundadoras de la objetivación utilitarista de la razón tecnocientífica sustentada en el economicismo exacerbado.

El tesoro que está custodiado en la estancia de Mmme. Panckoucke [estancia llena de juguetes rememorada por Baudelaire en su texto Moral del juguete], apunta hacia un estatuto más original de la cosa, sobre el que los muertos, los niños y otros fetichistas pueden darnos informaciones preciosas. Las investigaciones de Winnicott sobre las primeras relaciones entre los niños y el mundo exterior han llevado así a la identificación de un género de objetos, definidos por él como objetos transicionales, que son las primeras cosas (trozo de tela, de género o similares) que el niño aísla en la realidad exterior y de los que se apropia, y cuyo lugar está "en la zona de experiencia que está entre el pulgar y el oso de peluche, entre el erotismo oral y la relación 
objetual verdadera". No pertenecen por eso propiamente ni a la esfera subjetiva interna ni a la objetiva externa, sino a algo que Winnicott define como "área de la ilusión” en cuyo "espacio potencial" podrían a continuación situarse tanto el juego como la experiencia cultural. (...) Las cosas no están fuera de nosotros, en el espacio exterior medible, como objetos neutrales (objecta) de uso y de cambio, sino que son por el contrario ellas mismas las que abren el lugar original a partir del cual puede únicamente hacerse posible la experiencia del espacio exterior medible, es decir que están ellas mismas prendidas y comprendidas desde el comienzo en el topos outopos en el que se sitúa nuestra experiencia de ser-en-el-mundo. ${ }^{13}$

Deseo, memoria y experiencia se encuentran en la hora de la historia, en el presente. Lo que está pensando Agamben en Estancias, revisando obras como la de Benjamin, Marx, Baudelaire y Rilke, es la potencia de la obra de arte, y con ella la del hombre en su estancia en el mundo, para entrar en relación con la irrealidad y de ese modo apropiarse de la realidad sin asirla como un útil a disposición del homo sapiens. Entregarse en fin a la tarea contemporánea, comenzada por los críticos del capitalismo decimonónico, de imaginar en común poéticas (modos de hacer) co-habitacionales que logren ponerle freno al movimiento del progreso, y en esa detención darle paso a la imagen de otro mundo posible, una burbuja (según la esferología de Sloterdijk ${ }^{14}$ ) que interviene en la linealidad de la historia y de la política devastadora moderna, repasada por la investigacióncamino sebaldiana. Pues la historia, para Sebald, como para Benjamin y para Kluge ${ }^{15}$, no se reduce a la exposición gloriosa, intrigante o efímera de un pasado sepultado reconstruido por la pluma del historiador. La historia es para ellos la capacidad colectiva de interrumpir el continuum de la historia, e irrumpir en la materialidad y el sentido del presente vivido. Escribir y comprender la historia es hacer saltar la filosofía teleológica del historicismo y su direccionalidad hacia un destino glorioso o trágico (todo Sentido transcendente desaparece para el materialista histórico), y darse a la tarea ardua y siempre renovada de construir/especular, a partir de los materiales de tiempos cruzados, una esfera-mundo más justa e inclusiva. De modo que esta tarea es eminentemente política.

Para Benjamin no puede haber historia sin el efecto Medusa -sin la capacidad de interrumpir el movimiento histórico. (...) La mirada de la Medusa demora la historia en la esfera de la especulación, pone en corto circuito y, así, suspende la continuidad temporal entre el pasado y el presente. Este quiebre (...) posibilita la relectura y la reescritura de la historia, la puesta en práctica de otro modo de entendimiento histórico. ${ }^{16}$
13. Ibídem, p. 95.

14. Cf. SLOTERDIJK, Peter. Esferas I, 2002; Esferas II, 2006; Esferas III, 2006.

15. La figura de Kluge es un pilar en la reflexión ensayística de Sebald sobre el papel de la memoria en la historia natural de la destrucción. Cf. SEBALD, W.G. "Entre historia e historia natural. Sobre la destrucción literaria de la destrucción total", 2007, p. 64-91.

16. CADAVA, Eduardo. Trazos de luz. Tesis sobre la fotografía de la bistoria, 2014, p. 138. 
$\mathrm{Y}$ esa inmovilización es vista como una necesidad, pues para espíritus como Benjamin y Sebald es la catástrofe causada por el mismo hombre contra sí mismo en beneficio de unos vencedores, el sello de la historia moderna. Sello que para el historicismo positivista o no existe como tal, o bien es un sacrificio necesario para que el progreso y las luces de la civilización sigan abriendo caminos en medio de la barbarie.

Al prestar atención a lo que se ha ocultado o ignorado dentro de la historia, a la transitoriedad de los acontecimientos, a la relación entre cada momento dado y la totalidad de la historia, el materialista histórico busca delinear los contornos de una historia cuya chance depende de la capacidad de superar la idea de la historia como una mera

17. Ibídem, p. 141.

18. El narrador sebaldiano, historiador materialista heredero de Benjamin, sigue las huellas, los trazos fantasmales que se le aparecen en el camino de su viaje. Y lo que descubre es que éstas no son sino señales de las catástrofes generadas por los procesos llamados modernizadores-civilizatorios. Junto con el narrador, "percebemos que as marcas de decadência na verdade é o que em uma visão capitalista e consumista chamaria de modernização (...). Deste modo, Sebald lê a paisagem criada pela ideologia vigente como ruína. Ele entende que a cultura, o modo de vida, assim como os seus bens culturais, também fazem parte do espólio de guerra dos vencedores". MACIEL PEREIRA, G. "Algumas Reflexões sobre W. G. Sebald à luz de Walter Benjamin", 2011, p. 76.

19. Cf. SEBALD, W.G. Los anillos de Saturno, 2002, p. 11.

20. SEBALD, W.G. Campo Santo, 2007, p. 117.

21. Ibídem, p. 118.

22. MACIEL PEREIRA, Gerciano. "Algumas Reflexões sobre W.G. Sebald à Luz de Walter Benjamin”, 2011, p. 71.
Esas catástrofes se le aparecen, como si de una historia de aparecidos se tratase -con todo el horror que ello involucra-, al peregrino de Suffolk -la voz memoriosa a cargo de la narración en Los anillos de Saturno-; y en el recuerdo trabajoso de ese viaje por comarcas escasamente pobladas la investigación histórica y la imaginación asociativa (percepción de semejanzas y afinidades; recreación narrativa de sucesos y el universo material, emocional y afectivo en que tuvieron lugar, etc.) relevan los intrincados senderos de la memoria ${ }^{18}$. Una memoria que en un principio se vio obturada por el "horror paralizante" que le causó la contemplación de las huellas de la destrucción que, en aquel apartado lugar incluso, en Suffolk, retrocedían a un pasado remoto ${ }^{19}$. Pero que sin embargo, esa parálisis que lo llevó a ser internado en un estado casi vegetativo, es superada y a partir de allí el trabajo de la escritura/memoria comienza su compromiso con esas huellas, y los fantasmas que yacían sepultados en la mudez absoluta hablan a través de la voz del narrador devenida casi un médium. Esta lucha por la supervivencia en el hospital se convierte luego en una lucha contra "el arte del olvido" ${ }^{20}$ que el tiempo y la desmaterialización entrópica promueven, y que determinadas formaciones sociales con sus respectivas mnemotécnicas profundizan y potencian. No podemos dejar de notar que, tal como dijera Sebald respecto de la obra polifacética de Peter Weiss, "en esa reconstrucción, el sujeto artístico comprometido con la memoria (...) actúa también contra su propia persona, lo que, por su carácter doloroso, garantiza la permanencia del recuerdo"21. Siguiendo las reflexiones de Gerciano Maciel Pereira en torno a la narrativa sebaldiana a la luz de W. Benjamin, podemos decir: "em vez do silêncio, a complexidade do fato deve incentivar novas formas de narrar"22. Y así sucede. El sujeto asume la responsabilidad y el compromiso de representar acontecimientos horribles en las que un sinfín de esferas explotó por un ejercicio de violencia 
humana o por presiones de las fuerzas naturales. En el caso de la violencia cruenta (y por ello evitable) puesta en marcha por una maquinaria de poder ideológica anclada en el bumanismo colonialista antropocéntrico, la devastación surge como un daño enjuiciable (en términos morales). Lo que las narrativas del progreso expresan, sin embargo, es que el daño es un mal necesario, un sacrificio que debe hacerse para arribar a estados sociales cada vez más perfectos y confortables donde el individuo pueda gozar de la libertad que el sistema económico le ofrece.

Un apartado clave en esta historia en negativo de la Modernidad, donde la "idea de catástrofe que [se] desarrolla en esos panoramas no abre evidentemente perspectivas escatológicas, [ya que] es la designación de una destrucción que ha pasado al estado de permanencia"23, es el hecho históricamente nuevo de la destrucción total acaecida durante la Segunda Guerra Mundial. En una entrevista realizada a William Hazel en las inmediaciones de Somerleyton, el narrador descubre que en los años que siguieron al bombardeo británico sobre poblaciones alemanas, cuyo objetivo era destruir el espíritu de resistencia de la gente a partir de la aniquilación material de sus lugares de existencia, "nadie parecía haber escrito o recordar algo en aquel tiempo" ${ }^{24}$. La catástrofe desatada sobre zonas de vida humana produjo un shock en la experiencia inmediata de los supervivientes, quienes, despojados de sus normas sociales y reducido su universo material y anímico a escombros, comenzaron la labor titánica de la reconstrucción de sus vidas sin sentir, aparentemente, la necesidad de recordar ese tiempo infernal.

Batallar y resistir contra "la capacidad humana de reprimir todo recuerdo que pudiera estorbar la continuación de la vida" 25 es asumido como un imperativo moral por el narrador. No sólo al detallar cuantitativamente mediante un discurso desapasionado, renunciando al artificio, las consecuencias de las continuas destrucciones sufridas por las múltiples formas de vida (humana y no humana), sino acercándose en determinados pasajes al registro y al tono del reportaje, el informe o el documental. El trabajo de la memoria requiere una amplia investigación que dé cuenta y se haga cargo de las muertes y los vestigios perpetrados por los agentes de la destrucción. Porque, si la distancia objetiva que requiere el relato de la destrucción acerca la historia a la historia natural y parece equiparar el daño obrado por el imperio británico sobre el Congo o China a las fuerzas del océano embistiendo Dunwich, o a las de la tormenta arrasando arboles ancestrales en Ditchingham ${ }^{26}$, es el compromiso subjetivo y el ideal de lo verdadero expuesto en una escritura literaria heterogénea el que decide la posición del escritor/narrador del lado de los vencidos. Toma de posición
23. SEBALD, W.G. Campo Santo, 2007, p. 118.

24. Idem, Los anillos de Saturno, 2002, p. 48.

25. Idem, Campo Santo, 2007, p. 79 .

26. Cf. SEBALD, W.G. Los anillos de Saturno, 2002, p. 276-281. 
que se hace visible al instante que devela la responsabilidad ética de los agentes humanos de la destrucción.

27. SEBALD, W.G. Campo Santo, 2007, p. 80.

28. "no permite que la información permanezca como una simple cuenta de una catástrofe del pasado (...), el documento más reciente pierde su carácter inmediato por medio de procesos de reflexión que el texto ha elaborado. La Historia ya no es sólo el pasado sino que se extiende al presente en el cual el lector debe actuar". (La traducción es nuestra). Andrew Bowie citado en SEBALD, W.G. Campo Santo, 2007, p. 90.

29. En su análisis sobre los principios técnicos que estructuran la narrativa de W. G. Sebald, Ben Hutchinson reconoce entre ellos el principio de "montagem". Para un análisis más detallado sobre este tema Cf. HUTCHINSON, Ben, "Marinheiro ou camponês? Algumas reflexões sobre as leituras de Sebald do ensaio 'O narrador' de Walter Benjamin”, 2016, p. 85-107.

30. "O historiador/colecionador tem que ser seletivo e oportunista, não basta colher o escombros e fragmentos indiferentemente (...) deve se manter em constante vigília para as manifestações do passado, para as coincidências ou para os lapsos de imagens lampejados pela memoria involuntária. (...) W. G. Sebald estrutura quase todas as suas narrativas em cima de imagens involuntárias, sobre uma coincidência em que o passado retorna com os seus mortos e o interpela a escrever sobre ele". MACIEL PEREIRA, Gerciano. "Algumas Reflexões sobre W. G. Sebald à Luz de Walter Benjamin", 2011, p. 78-79.

\section{La responsabilidad ética de la rememoración / recordación: el historiador materialista y la redención}

Colmar la laguna de la memoria, y abocarse a la lectura denodada de los trazos y las huellas dejadas por las catástrofes, encarna la axiomática de la historiografía materialista legada por Benjamin en sus tesis "Sobre el concepto de historia", donde la historicidad no es un relato o una forma de conocimiento sobre el pasado que fue, sino que conforma un tipo de praxis que envuelve al pasado y al presente en una dialéctica que destituye sus posiciones en la línea cronológica. En Los anillos de Saturno, el informe sobre las calamidades que sin pausa organizamos la descripción de la vida en los momentos de desintegración, así como el resto que queda como ruina de esos acontecimientoses asumida por un cuerpo (y una voz) que se ha delegado a sí mismo (imperativo categórico) la rememoración y la transmisión de la información objetiva que guarda, aceptando el reto de vivir con el riesgo de la memoria. Riesgo que quienes depositan el sentido del porvenir al olvido y la vivencia sin experiencia "nada saben del potencial positivo de la melancolía"27 a la que puede arrastrar, y de hecho lo hace en este caso, al sujeto memorioso.

Esta escritura asume una responsabilidad de la historia con la historia misma, una responsabilidad que se instala en la actualidad en vistas al por-venir. Sebald, al igual que Kluge,

\begin{abstract}
does not allow the data to stand merely as an account of a past catastrophe (...), the most inmediated document [...] loses its unmediated character via the processes of reflection the text set up. History is no longer the past but also the present in which the reader must act. 28
\end{abstract}

El historiador busca en el lector un aliado para que el recuerdo del horror, convertido en experiencia a partir de la narración -a través de la inserción en una cadena de significados que opera por semejanzas y afinidades desmontando la historia para montar ${ }^{29}$ el estado de permanencia de la catástrofe en la historia ${ }^{30}$-, se afirme como una vía de acceso a la restitución de un mundo donde el daño, la violencia y las injusticias no continúen siendo la sombra del futuro en la Tierra.

En el camino de Suffolk, on the empty and dark road (en el vacío y oscuro camino), Sebald encuentra personas que, como 
él, aceptaron volver tras las huellas del pasado que habían perdido y cuyos recuerdos el tiempo fue desdibujando de la memoria. En Middleton visita a su amigo Michael Hamburger, un exiliado alemán en Inglaterra, quien, terminada la Segunda Guerra, decidió regresar a su ciudad natal en ruinas, para de las cenizas de aquel paisaje estremecedor (que coincidían con los vestigios de su memoria) recuperar la densidad de su infancia en Berlín. Al revisar las notas autobiográficas de Michael, el narrador constata el esfuerzo y la penuria de ese trabajo de rememoración. De pronto, la totalidad del pasado, de ese mundo tapado por los restos de la masacre y la locura parecen depender de la fragilidad de un cuerpo entregado a la fuerza de sus recuerdos.

Era como si ahora todo dependiese de mí [anota Michael], como si toda la historia pudiera hacerse recuperable por medio de un esfuerzo mental insignificante, como si, sólo con que yo lo deseara, viviese la abuela Antonia, que se había negado a ir con nosotros a Inglaterra (...) Sólo era necesario un instante de máxima concentración, la composición silábica de la palabra oculta en el enigma y todo volvería a ser como antes. ${ }^{31}$

A través de la figura de Michael descubrimos que nuestro narrador es también un exiliado, y un docente universitario atormentado por la escritura. Lo expresa él mismo de la manera siguiente, luego de preguntarse por la extrañeza que causan las afinidades electivas y las correspondencias entre vidas alejadas en el tiempo, vidas marcadas, signadas quizás, por una serie de pensamientos, prácticas y sucesos que estructuran su carácter ${ }^{32}$ :

No mucho más extraño es que yo haya franqueado la aduana inglesa por primera vez treinta y tres años después que Michael, que ahora mismo piense en abandonar mi profesión docente como él ha hecho, que él se atormente con la escritura en Suffolk y yo en Norfolk. ${ }^{33}$

Ese tormento puede leerse como parte del proceso de autodestrucción soportado conscientemente por el escritorartista en su empresa rememorativa de matiz marcadamente ético. En una sociedad donde la modernización del mundo de la vida ha ido acrecentando el dictum profano de la modernidad, según el cual Modernidad "significa la época que vive orientada hacia el futuro, que se ha abierto hacia lo nuevo futuro" 34 por medio del concepto de progreso ${ }^{35}$, dando la espalda a todo aquello que se perciba como pasado, hay quienes sienten esa mirada comprensiva del mundo como un déficit. Una falta que toca la negligencia y la indiferencia al descubrir, por vías anamnéticas e investigaciones detalladas ${ }^{36}$, que en ese pasado existen muertos que todavía claman por su redención, ya no
31. SEBALD, W.G. Los anillos de Saturno, 2002, p. 191.

32. En este caso Sebald rastrea las correspondencias entre la figura y la obra de Michael y las de Holderlin (Cf. SEBALD, W.G. Los anillos de Saturno, 2002 p. 194-195). Una investigación futura podría a su vez entablar una puesta en relación entre Sebald y Holderlin para analizar el sentido de lo trágico presente en ambos autores. Insistimos en llamar Sebald al narrador de Los anillos de Saturno, pues datos como los expuestos en el pasaje sobre Hamburger, al igual que guiños de fechas o nombres hacen de indicios para que el lector reconstruya la identidad fantasmática del narrador. Algunos de esos guiños o signos son los siguientes: "en la inauguración de la casa, en mayo de 1944, es decir, justo trescientos años antes de mi nacimiento" (SEBALD, W.G. Los anillos de Saturno, 2002, p. 94); "la visita a la antigua Pinacoteca y a la tumba de mi santo, san Sebaldo, en Nuremberg" (Ibídem, p. 96). Del mismo modo, en el relato que está acompañado de imágenes y fotografías, existe una en la que aparece un sujeto de frente apoyado sobre un enorme olmo; el sujeto fotografiado, es posible reconocerlo a simple vista, es Sebald mismo, y el narrador refiere a la imagen diciendo: "El cedro libanés en el que yo, desconociendo aún todo lo malo que sucedería, estoy apoyado, es uno de los tantos árboles plantados en la fundación del parque, que, como se ha dicho, han desaparecido" (Ibídem, p. 276).

33. SEBALD, W.G. Los anillos de Saturno, 2002, p. 195.

34. HABERMAS, J. El discurso filosófico de la modernidad, 2010, p. 15. 
35. Progreso a través del cual "se constituye la idea de historia como un proceso unitario (...) a la vez que el tiempo es vivido como recurso escaso para la solución de problemas que apremian, es decir, como presión del tiempo." (HABERMAS, J. El discurso filosófico de la modernidad, 2010, p. 16).

36. Esta sinergia entre memoria e investigación también es resaltada por Maciel Pereira en su ensayo sobre la narrativa sebaldiana. Él apunta que: "Sebald se mostra um narrador atento e suficiente capaz de captar a fugaz imagem do passado, para fazer dela um fragmento privilegiado que lhe permitirá reler a História”, y prosigue: "Este extremo acaso, que impõe uma ascese, deve ser acompanhado de uma investigação, pois este traz sempre uma verdade inusitada do passado" (MACIEL PEREIRA, Gerciano. "Algumas Reflexões sobre W. G. Sebald à Luz de Walter Benjamin”, 2011, p. 79-80).

\section{Cf. REYES MATE,}

M. Medianoche en la historia. Comentarios a las Tesis de Walter Benjamin "Sobre el concepto de historia", 2009.

38. La empatía, enlazada a la responsabilidad, se erigen como categorías éticas (conformando el impulso moral) en el camino hacia la justicia que busca establecer el escritor a través del recuerdo. En Sobre historia natural de la destrucción, Sebald deja sentado, al leer el proyecto literario de Nossack sobre la recomposición objetiva de las experiencias vividas por los supervivientes alemanes durante la catástrofe del bombardeo británico en la década de 1940: "La extrañeza de Nossack se debe a que (...) se enfrenta con una insensibilidad moral que raya en lo inhumano. No se espera de una colonia de insectos que, ante la devastación de una construcción vecina, en el momento de la parusía cristológica, sino una redención que, con Reyes Mate, llamamos hermenéutica, pues se trata del sentido de vidas subyugadas ${ }^{37}$. Es esa falta la que, movida por la empatía ${ }^{38}$, lleva al narrador a afirmar que el ideal de lo verdadero, de lo acaecido durante una catástrofe organizada por la voluntad de poder de determinados agentes sociales, "se muestra como el único motivo legítimo para proseguir la labor literaria"39.

Se mira hacia el pasado, se lee las ruinas materiales exhumando los fantasmas que piden en un terrorífico grito, inaudible para la mayoría, se los escuche, no movidos por un instinto romántico que llevaría a contemplar ensoñadamente esas ruinas, sino porque el sujeto siente el desasosiego de la violencia estructural que anida en el mundo del presente. Al respecto señala Carlos Thiebaut: "La catástrofe de la que nos habla Sebald no es inmune a la imputación de responsabilidad. (...) Y justamente porque es responsable nos desasosiega, como a Zuckerman, y nos interpela" ${ }^{40}$. Y en ese desasosiego se agita la recordación, la cual, al igual que las Tesis de Benjamin, llevan clavadas una astilla del mesianismo. Pues, como se muestra al rememorar (a partir de un sueño) la estancia del narrador en la casa señorial de los Ashbury, hay vidas enteras marcadas por el hundimiento abrumador de todo un universo social producido por máquinas ideológicas de poder. Por las venas del tiempo viajan las células de la catástrofe y quienes caminan entre los vivos, sin darse cuenta, lo hacen en la fila de los muertos. El trabajo de la memoria, precisamente, en el caso ejemplar de los Ashbury, busca dar un sentido a todo ese mundo extraño, casi siniestro que se ha declarado inútil para la vida cotidiana.

En la biblioteca de la casa de tres pisos sitiada en las Slieve Bloom Mountains de Irlanda, el relato de la señora Ashbury ${ }^{41}$, acompañado de imágenes cinematográficas, hace las veces de comprensión dialéctica de las desavenencias constantes sufridas por ella y sus hijos a través de los años. A partir de la narración del incendio de las casas señoriales de la aristocracia irlandesa identificada con la odiada autoridad nacional inglesa, accedemos a un mundo totalmente en ruinas. La paulatina desintegración material de los restos dejados por el fuego provoca la latente desintegración de todo el entramado psíquico que sostenía aquel mundo ${ }^{42}$. La reconstrucción narrativa de la catástrofe incendiaria sufrida por sus ancestros y el pueblo al que pertenecían durante la cuestión irlandesa -guerra civil- conducen a una reflexión cargada de pesimismo por parte de la dama:

no me quería convencer de que la sociedad a la que pertenecíamos se había desmoronado hacía ya tiempo. (...) Todas las iniciativas que hemos acometido, las interminables labores de costura de las chicas, la explotación del huerto que Edmund comenzó una vez, el plan de admitir 
huespédes, toda ha fracasado. (...) Todos nosotros somos unos señores, inservibles para la vida cotidiana. (...) It seems to me sometimes that we never got used to being on this earth and life is just one great, ongoing, incomprehensible blunder. ${ }^{43}$

La astilla de mesianismo significa una hendija abierta a la esperanza, a que las cosas cambien. Leyendo al Benjamin de las Tesis afirma Reyes Mate: "La recordación permite salvar el pasado al dar sentido a la injusticia pasada, aunque nadie garantice que se le haga justicia. La redención que él alcanza es la del sentido" $" 4$.

La esperanza aparece en momentos de peligro, pues no hay esperanza que no se alimente en algún punto de una lectura trágica de la luminosidad del mundo. Luminosidad que coincide con la visión progresista de la historia, la cual, como hemos venido exponiendo a lo largo de este trabajo, inculca el ideal de un proceso que acrecienta potencialidades latentes en el hombre y la humanidad dirigiéndolas siempre hacia un estadio superior. Para lograr avanzar en esa carrera debe haber costos a pagar, partes del estadio inferior (anterior) que deben ser eliminados, sacrificados, para alcanzar la meta inmediata siguiente. Es decir que debe haber víctimas, que no son percibidas como tales, a las que habrá que doblegar mediante la violencia y el dolor. Dice Reyes Mate: "Lo grave de esta visión progresista de la historia no es tanto que produzca víctimas, sino que las justifique y, por tanto, las reproduzca indefinidamente" ${ }^{45}$. La esperanza resiste para en lo posible acabar con esa trama homogénea, ya que ella, en su aferrarse a la imagen de un futuro más justo para todos, resguarda el pensamiento de que "en la idea de felicidad late inexorablemente la de redención" ${ }^{46}$. Redención bajo la cual abraza las violencias silenciadas, negadas u olvidadas del pasado, convencido el sujeto de esperanza de que, como escribiera Benjamin, "existe un misterioso punto de encuentro entre las generaciones pasadas y la nuestra" ${ }^{\prime}$, hecho que lo lleva a hacerse responsable de darles una entidad en el presente pues "nos ha sido dada una débil fuerza mesiánica sobre la que el pasado tiene derechos"48. Una vez más el filósofo español Reyes Mate aclara estas ideas:

Desde el momento en que el pasado no es cosa exclusiva de la ciencia histórica sino también de la recordación, la memoria puede abrir expedientes que la historia da por archivados (...). La memoria de las injusticias pasadas proporciona una experiencia singular: no nos permite cerrar los oídos a los gritos de las víctimas que claman por sus derechos. ${ }^{49}$

Este concepto de historia cuyo corazón es la memoria ${ }^{50}$ se enuncia de modo explícito en las antesalas del diario de viaje que en parte es Los anillos de Saturno. Se trata del segundo se quede paralizada de dolor. Sin embargo, de la naturaleza humana sí cabe esperar cierto grado de empatía. En ese sentido, el mantenimiento del orden pequeñoburgués del café de sobremesa en los balcones de Hamburgo a finales de julio de 1943 tiene algo de espantosamente absurdo y escandaloso" (SEBALD, W.G. Sobre la historia natural de la destrucción, 2003, p. 51-52).

39. Ibídem, 2003, p. 68.

40. THIEBAUT, Carlos. "El relato del daño como historia natural: a propósito de W. G. Sebald". Boletín de Estética, Año XI-Primavera 2014/ No 29. p. 5-91.c

\section{En este pasaje se}

hace explicito el tema de la comunicabilidad de la experiencia vivida y la de su asimilación en la vida de una comunidad. A la hora de reconstruir un pasado signado por el shock de una devastación organizada ("No creo, decía la señora Ashbury, que podamos hacernos una idea siquiera aproximada de lo que podría estar pasando por las mentes de los afectados al ver algo asî" (SEBALD, W.G. Los anillos de Saturno, 2002, p. 230)), las múltiples fuentes de información conviven en la voz de quien se hace cargo de ese recuerdo: "Aparte de mi marido, que era extremadamente reservado, decía la señora Ashbury, como fuente de información sobre la cuestión irlandesa por un lado trágica, por otro ridícula, no tenía más que las leyendas que en el transcurso de la decadencia paulatina se habían originado en las mentes de los sirvientes que pertenecían a la historia, por así decirlo, junto con el resto del mobiliario que habíamos heredado" (Ibídem, p. 229).

42. Cf. SEBALD, W.G. Los anillos de Saturno, 2002, p. 229-233. 
43. "A veces pienso que nunca nos acostumbramos a vivir en esta Tierra y que la vida es una gran, incomprensible torpeza siempre en curso". (La traducción nos pertenece). SEBALD, W.G. Los anillos de Saturno, 2002, p. 234-235.

\section{REYES MATE, M.}

Medianoche en la bistoria.

Comentarios a las Tesis de Walter

Benjamin "Sobre el concepto de historia”. 2009, p. 28.

45. Ibídem, p. 41.

46. BENJAMIN, W. "Tesis II" citado en REYES MATE. Medianoche en la historia. Comentarios a las Tesis de Walter Benjamin "Sobre el concepto de historia", 2009, p .67

47. Ibídem, p. 67.

48. "Benjamin invierte el signo de la orientación radical hacia el futuro que caracteriza en general a la modernidad, hasta el punto de trocarla en una orientación aún más radical hacia el pasado. La esperanza de lo nuevo futuro sólo se cumple mediante la memoria del pasado oprimido. El signo de una detención mesiánica del acontecer lo entiende Benjamin como 'oportunidad revolucionaria en la lucha por el pasado oprimido' (tesis 17)". HABERMAS, J. El discurso filosófico de la modernidad, 2010, p. 22.

49. REYES MATE, M.

Medianoche en la historia. Comentarios a las Tesis de Walter Benjamin "Sobre el concepto de historia", 2009, p. 75.

50. Recordar etimológicamente significa volver a pasar por el corazón. La historia que pasa por la memoria abandona la materia muerta del papel y late en el corazón de un sujeto individual o colectivo puesto a recordar. Los afectos y las pasiones imprimen y dan vida a lo que la ciencia histórica había relegado a las cenizas de la escritura. epígrafe del libro, un extracto de una carta enviada por Joseph Conrad a Margueritte Poradowska donde deja escrito: "Il faut surtout pardonner à ses âmes malheureuses qui ont élu de faire le pèlerinage à pied, qui côtoient le rivage et regardent sans comprendre l'horreur de la lutte et le profond désespoir des vaincus" ${ }^{51}$. La rememoración sebaldiana (recordación benjaminiana en la terminología de Reyes Mate) muestra las imágenes del horror, expone a los vencidos y les hace un lugar en la historia. Al "dar a conocer la gran corriente de la fatal tendencia seguida hasta ahora por la historia, en sus detalles" 52 , la narración compuesta de historias varias se erige, en una de sus múltiples dimensiones, como una crítica desesperada al proceso civilizatorio de modernización.

¿Podemos hablar, sin embargo, de esperanza o mesianismo benjaminiano en un relato donde lo que parece primar es una lectura pesimista de la historia? De hecho, el repaso tortuoso y melancólico de aquel peregrinaje por Suffolk, repaso que comenzó en un estado casi vegetativo en un hospital, casi que se cierra con estas palabras: "cuando vuelvo a pensar en nuestra historia, casi sólo compuesta de calamidades" ${ }^{53}$. Sostenemos que sí, existen indicios en el relato que nos llevan más allá del pesimismo e intentan superarlo. Una de esas instancias es la del duelo o, también, el acto de llevar luto ${ }^{54}$, costumbre extinta en las sociedades del capitalismo tardío ("Anne, que había estado descansando un par de horas, entró en la habitación y se sentó con nosotros. No puedo recordar si fue ella quien llevó la conversación a que hoy por hoy nadie lleva luto" ${ }^{55}$ ). La memoria que focaliza sus energías en los muertos e injusticias del pasado quiere, no sólo, incluirlos en un espacio espiritual que los redima, sino, por sobre todo, transformar el presente, pues en él siguen produciéndose una y otra vez las calamidades y catástrofes que el progreso invisibiliza y empuja al olvido, acumulando ruina sobre ruina mientras sigue su marcha imparable hacia adelante. En este aspecto, las figuras de los monumentos belgas construidos con las riquezas acumuladas a costa de los cadáveres de los explotados del Congo ${ }^{56}$, así como la "construcción, decoración y mantenimiento de suntuosas residencias veraniegas y palacios" ${ }^{57}$ en ciudades como La Haya y Londres, son un testimonio material de la violencia impuesta en escalas inimaginables por la fuerza del capital. Fuerza y violencia que continúan su movimiento inercial, dejando vestigios, desechos al costado del camino. El narrador da el ejemplo, extraído de una conversación con un holandés llamado Corneluis de Jong, de la relación existente entre la historia del azúcar y la del arte, vinculadas por el eslabón económico, las ingentes ganancias producidas por la actividad azucarera en manos de unas pocas familias a principios del siglo XX. 
Fue Cornelios de Jong quien me hizo ver que el origen de muchos museos importantes, como el Mauritshuis de La Haya o el Tate Gallery de Londres, se remonta a fundaciones de dinastías azucareras o de algún modo ligadas al comercio del azúcar. De Jong decía que el capital acumulado de diferentes formas de la economía esclavista en los siglos XVIII Y XIX sigue estando en circulación, produce intereses e intereses de los intereses acumulados, aumenta y se multiplica, sin cesar un solo momento sin rendir nuevos frutos. Desde siempre, uno de los medios más eficaces para la legitimación de estos fondos ha sido el patrocinio del arte, la compra y la exposición de obras. ${ }^{58}$

\section{Comunidad fantas(m)eada: de fantasmas y resistencias en medio de la luminosidad del mundo}

El gesto del recuerdo ya es en sí un desvío de las rutas iluminadas por las luces del capitalismo tardío. Hacer el viaje a pie, a la orilla del Mar del Norte, tiene su correlato en el plano del sentido de la narración, en el hecho de asomarse a los bordes de la historia moderna del progreso para detener la mirada en los desechos, los restos desatendidos por ese mismo proceso sacrificial. Un proceso que, como señalan ciertos discursos escatológicos, ya sean tecnófilos o tecnófobos, nos llevará hacia el Fin del mundo (Tierra) o de la especie humana tal como la conocemos hasta hoy. Y ese gesto de la memoria, introducido en una narración heteróclita, persiste en tanto crítica que busca dar una alternativa, abrir otro mundo posible, a la historia moderna que ella misma devela.

Nuestra lectura es contraria a la conclusión a la que llega Huysen sobre el pensamiento sebaldiano. Según el crítico alemán, Sebald, "who rewrites the texts of the past and who remembers the concrete texture of the lives lost" 59 , en sus narraciones, pero sobre todo en su ensayo Sobre la bistoria natural de la destrucción aparecido en alemán en $1999^{60}$ estaría atrapado en el pasado, cuya lectura desesperada y melancólica no le permite avizorar ningún recomienzo. La rememoración, sobre todo en los `90, lo habrían conducido a, como piensa Huyssen citando al mismo Sebald, "to interpret the most recent historical developments simply as natural history" (interpretar los desarrollos históricos más recientes simplemente como historia natural ${ }^{61}-$ la traducción es nuestra- $)^{62}$ por lo cual no sólo no hay recomienzo sino tampoco un futuro. No hay, dice Huyssen, cambio (Wende) posible. La destrucción es total, el discurso sebaldiano quedaría así atrapado, para el crítico alemán, dentro de las narrativas tecnófobas catastrofistas o apocalípticas.
51. SEBALD, W.G. Los anillos de Saturno, 2002, p. 7. "Sobre todo hay que perdonar a las almas infelices que eligieron hacer el peregrinaje a pie, que se relacionan con la orilla $y$ que miran sin entender el horror de la lucha y la profunda desesperación de los vencidos" (La traducción nos pertenece).

52. Idem, Campo Santo, 2007 , p. 89.

53. Idem, Los anillos de Saturno, 2002, p. 310.

54. Cf. SEBALD, W.G. Los anillos de Saturno, 2002, p. 310.

55. SEBALD, W.G. Los anillos de Saturno, 2002, p. 201.

56. Ibídem, p. 132-133.

57. Ibídem, p. 208.

58. Ibídem, p. 208.

59. HUYSSEN, Andreas.

"Rewritings and New

Beginnings: W. G. Sebald and the Literature on the Air War", 2003, p. 154. "Quien reescribe los textos del pasado y recuerda la textura concreta de las vidas perdidas" (la traducción es nuestra).

60. Este ensayo, aparecido como un libro autónomo, es, como bien apunta Huyssen, una reescritura de un texto anterior escrito en 1982, y publicado en lengua española en el libro Campo Santo. Según Huyssen en esa reescritura desaparece la noción fuerte de recomienzo (new beginning), y Sebald se habría inclinado por una interpretación naturalista de las catástrofes impulsadas por el sistema económico y la técnica en su fase industrial, dejando de lado los aspectos sociales y políticos de la destrucción. De hecho la bistoria natural de la destrucción no sería sino la inevitable historia técnica de la destrucción (Cf. 
HUYSSEN, A. "Rewritings and New Beginnings: W. G. Sebald and the Literature on the Air War", 2003, p. 155). Esta lectura es contraria, como puede apreciarse, a nuestra lectura. El aspecto político y la responsabilidad de los agentes de la destrucción no desparecen en Sebald, así como tampoco lo hace la dimensión mesiánica de la Tesis IX de Benjamin y su ángel de la historia. Para Huyssen, el texto de 1999 "ends with the familiar passage from Walter Benjamin's thesis about the angel of history, but the messianic dimension inherent in Benjamin's thought, even at its most desperate and pessimistic, no longer finds a place in Sebald. It is as if history itself had been bombed into oblivion" ("termina con el conocido pasaje sobre la tesis del ángel de la historia de Walter Benjamin, pero la dimensión mesiánica inherente al pensamiento de Benjamin, incluyendo lo más desesperado y pesimista, no encuentra ya lugar en Sebald. Es como si la historia en si misma hubiera sido fulminada en el olvido" (Ibídem, p. 155; la traducción es nuestra).

61. En "Entre historia e historia natural. Sobre la descripción literaria de la destrucción total" Sebald cerraba sus reflexiones contraponiendo a Kluge con aquellos que sostienen una visión naturalista de la catástrofe como hecho humano. Kluge, por medio de su escritura, "trabaja para regenerar la memoria colectiva de sus contemporáneos" (SEBALD, Campo Santo, 2007, p. 90) y, ubicándose en el margen exterior de una civilización según todas las apariencias orientada a su fin, no cede a la tentación de una interpretación puramente naturalista de los acontecimientos históricos más recientes. Esto quiere decir,
En Los anillos de Saturno, viaje geográfico y a la vez narrativo emprendido bajo el signo de Saturno, el signo de la melancolía, la demora, y la tristeza, el acercamiento a las catástrofes del pasado organizadas por el hombre u ocurridas por efecto de las fuerzas naturales ${ }^{63}$ parecen asegurar la presencia de una filosofía pesimista de la historia sin un espacio para que un cambio se produzca. No obstante, la recolección de vidas o modos de vida y prácticas rescatadas por la recordación (para hablar con Reyes Mate) y la voz del narrador, tales como la del escritor FitzGerald, o el campesino Alee Garrard, o los cuidados del jardinero Hazel junto con sus trabajos para recopilar información sobre los bombardeos de la guerra aérea de 1940, al igual que la trayectoria memoriosa de Hamburger, o la capacidad incomprensible del gigante Squirrel para a pesar de su total amnesia recordar a los muertos, las costumbres de los pescadores de arenques, la lucha de Casement, los diarios de Korzeniowski, los escritos precursores de Thomas Browne: todos ellos conforman una constelación que apunta hacia una alternativa a la racionalidad tecnocientífica con su lógica del gasto permanente, la acumulación económica y la violencia sacrificial ejercida sobre seres humanos y no humano ${ }^{64}$. Al exhumar esas prácticas, y vidas individuales o colectivas y restituirles un lugar en el presente de la narración (muchas veces se les restituye su voz mediante el estilo indirecto ${ }^{65}$ ), la fuerza mesiánica débil aparece en el relato, tenue, como la fosforescencia (fantasmal) del arenque muerto. Se trata, podríamos decir, de una comunidad de fantasmas que brillan al margen de la luminosidad del mundo moderno. Son fantasmas, literalmente aparecidos que irrumpen en medio de la negra oscuridad con que se escribe esta historia de catástrofes. Se le aparecen al narrador anamnético, evocados por correspondencias casi epifánicas, diría Kuffer, en un rayo ${ }^{66}$. Un rayo que cruza el espacio abigarrado del pensamiento; a veces puede partir de un sueño, o de un recuerdo avistando el horizonte, o en el caminar vagabundo, pero siempre es la memoria la que los salva al contarlos, al construir ${ }^{67}$ una historia desatendida por el historicismo lineal, el del tiempo vacío de los vencedores del progreso y la civilización.

Tenues, alejados, al margen, como viviera FitzGerald por decisión propia, como un ermitaño. En personajes como este escritor melancólico el narrador nos ofrece modos de habitar la Tierra alternativos, ubicados por fuera de la compulsión del consumo y la ostentación material que pospone la realización del deseo indefinidamente. FitzGerald renunció a la fortuna familiar y abandonó la casa "guarecida de pesadas alfombras, muebles doradas, obras de arte y trofeos de viaje" y se instaló "en un cottage diminuto, de dos habitaciones al borde del parque" ${ }^{68}$. En ese retiro dedicó su vida a las lecturas en las lenguas muertas más diversas, a la redacción de cartas, a la 
compilación de palabras y frases para un glosario del lenguaje de la navegación y de la vida espiritual. Entre estas costumbres y acciones inútiles, improductivas económicamente, Edward FitzGerald se enfrascó con predilección en la correspondencia de épocas pasadas, como la de madame de Sevigné, "quien para él era mucho más real que sus amigos aún con vida". Asimismo tradujo El rubaiyata del persa medieval Omar Kayam, trabajo que él mismo "denominó un coloquio con el muerto, de quien intentaba darnos noticias" ${ }^{69}$. Este excéntrico escritor del siglo XIX habitante de Suffolk se sentía extemporáneo a las prácticas de los de su clase (de la que se alejó desde muy joven), terratenientes o comerciantes acaudalados que querían sacar de sus posesiones todo el beneficio posible, explotando la tierra.

Están talando todos los árboles y arrancando todos los arbustos, se quejaba. Pronto los pájaros no van a saber adónde ir. Todos los pequeños bosques están desapareciendo, los lindes de los caminos, donde en primavera crecían prímulas y violetas están arados y nivelados y cuando ahora se pasea desde Breedfield hasta Hasketon por uno de los senderos, antaño tan hermosos, se tiene la sensación de estar atravesando un páramo. ${ }^{70}$

Quizás por ello entabló coloquios con los muertos, con los fantasmas que desde la escritura le hablaban y a través de los cuales se sentía acompañado. Después de 1860 pasó la mayoría del tiempo a la orilla del mar en su yate Sacandal, hasta que en 1869 "se instaló en su último domicilio, una casa de granjero situada en la periferia de la ciudad" caracterizó siempre, con sus pretensiones extremadamente humildes. Rodeado por el fragor de la naturaleza, cuando hacía buen tiempo se sentaba en el jardín disfrutando del vuelo de las blancas palomas, o admirando desde su ventana la pradera de gansos rebordeada de árboles. "Y en esta soledad vivía extremadamente contento, tal como se puede leer en sus cartas"72, aunque por épocas lo asolaran los demonios azules de la melancolía. Ese retiro en cierto modo consciente de los ritmos naturales, y respetuoso de la pluralidad de formas de vida, lo convierten en un trazo que delinea un habitar inocente. Es este un habitar que sabe de la transitoriedad de las formas que aparecen y desaparecen en la Tierra, y que en ese proceso descubre el puesto del hombre en el Cosmos, como uno más entre los seres, no el llamado a dominar la totalidad de lo existente para vivir en el confort o el desconocimiento indiferente de la muerte propia y ajena. La vida se siente como un don, un regalo, y el paisaje es vivido como una esfera multirrítmica, policroma, que como desaparecerá y se perderá en la noche de los tiempos, cobra un significado nuevo e inusitado. Así debió sentirlo FitzGerald, imagina el narrador, la tarde antes de su muerte en el vagón que lo llevaba a Merton: a interpretar la historia como lo hace Stanislaw Lem, dice Sebald, "como la consecuencia catastrófica, anunciada hace tiempo por la fisiología demasiado complicada del ser humano, el desarrollo de su mente hipertrofiada y sus medios técnicos de producción, de una antropogénesis basada ya ab initio en errores de la evolución” (Ibídem, p. 91).

62. HUYSSEN, A. "Rewritings and New Beginnings: W. G. Sebald and the Literature on the Air War", 2003, p. 156.

63. Cf. SEBALD, W.G. Los anillos de Saturno, 2002, p. 170-171; 276-279.

64. La lista es interminable: árboles y bosques enteros, pájaros como el faisán (Cf. SEBALD, Los anillos de Saturno, 2002, p. 237-239), arenques, ríos y otras reservas de agua dulce y salada, paisajes naturales entendidos como ecosistemas, etc.

65. Paula Kuffer también se percata de este motivo propio de la narrativa sebaldiana: "sus textos se basan en relatos contados, en fuentes segundas, ponen en escena el habla de otra persona" (KUFFER, Paula. "Representación, melancolía y resistencia: el materialismo espectral de W. G. Sebald", 2014-2015, p. 20).

66. En la Tesis V escribía Walter Benjamin: "La verdadera imagen del pasado se desliza veloz. Al pasado sólo detenérsele como una imagen que, en el instante en el que se da a conocer, lanza una ráfaga de luz que nunca más se verá" (Benjamin en REYES MATE, M. Medianoche en la bistoria. Comentarios a las Tesis de Walter Benjamin "Sobre el concepto de historia”, 2009, p. 107). En su Explicitación de la Tesis V Reyes Mate afirma que "Benjamin quiere precisar cómo tiene que habérselas con el pasado el historiador de su escuela [el historiador materialista]. Ese 
pasado, empieza diciendo, no está ahí petrificado, en espera de que el historiador de turno lo analice. Es un pasado que se mueve y se mueve velozmente. Conocerlo es fijar una imagen de él, asunto nada fácil, ya que sólo bay un instante en que su aparición se cruza con nuestra mirada. (...) Los historicistas lo tienen más fácil. Ellos están convencidos de que la verdad del pasado no se les puede escapar porque siempre está ahí, quieta, a la espera de que alguien venga y se la lleve. Para el nuevo historiador esa seguridad de los historiadores es una angustia. No tiene la certeza de ellos porque sabe que el pasado no está ahí, sino que ese pasado que él trata de conocer porque es un desconocido sólo está ahí un instante. Y él no puede marrar la captura porque lo que está en juego es algo más que conocer, algo más que añadir un apartado a la vieja historia de la humanidad, algo más que enriquecer los anaqueles de la biblioteca con un nuevo tratado. Se trata de salvar ese pasado y para ello esa imagen fugaz tiene que quedar grabada en la placa del presente. La memoria es salvación del pasado y del presente. Salvación del pasado porque gracias a la nueva luz podemos traer al presente aspectos desconocidos del pasado; y del presente, porque gracias a su presencia el presente puede saltar sobre su propia sombra, es decir, puede liberarse de la cadena causal que lo trajo al mundo." (Ibídem, p. 108-109) (El subrayado es nuestro).

67. Cf. Benjamin Tesis XVVII en REYES MATE, M. Medianoche en la historia. Comentarios a las Tesis de Walter Benjamin "Sobre el concepto de historia”, 2009, p. 261-274.

68. SEBALD, W.G. Los anillos de Saturno, 2002, p. 213-214. (El subrayado es nuestro).

69. Ibídem, p. 214-215.

70. Ibídem, p. 216-217.

71. Ibídem, p. 219. (El subrayado es nuestro).
No se nos ha transmitido lo que pudo haber agitado el pecho de FitzGerald, mientras, recostado en los cojines de su vagón, veía cómo desfilaban arbustos y trujales, o quizá fuera como entonces cuando, de camino en el coche del correo de Leicester a Cambridge, se sentía como un ángel al mirar el campo en el estío, porque de pronto, sin haber sabido nunca por qué, se le llenaban los ojos de lágrimas de felicidad. ${ }^{73}$

Alee Garrad es otro de los virtuales habitantes de esta comunidad fantaseada, de esta comunidad de fantasmas. Comunidad fantas(m)eada. Comunidad de fantasmas, latencias del pasado, lo sido (diría Benjamin) que, cancelado por la violencia del progreso dogmático, aún sigue abierto como posibilidad, alternativa al capitalismo y la racionalidad tecnocientífica, para el porvenir. Fantasmas que hacen comunidad desde el momento en que sus prácticas intentan ser un modo de habitar que cuide y vele por la vida en todas sus formas. Comunidad fantaseada, imaginada pues no existe hoy, plenamente, en nuestro mundo globalizado. En este caso, el de Ale Garrard, se trata de un hombre que vive en el presente del narrador, y con el cual éste mantiene un encuentro. Sin embargo, su estilo de vida lo torna una especie de fantasma, un aparecido que interrumpe la lógica del universo $24 / 7$ y sus prácticas de consumo insomne, individualismo y derroche explotador hiperproductivo. Garrard, nos informa el relato, vive en una zona casi despoblada de Yorford, en las afueras de Harleston, y "lleva más de dos décadas construyendo un modelo del templo de Jerusalén"74. Su meta es llegar a reconstruir en miniatura dicho templo tal como había sido al comienzo de nuestra cronología. El secreto de su trabajo, que lo ha ido alejando cada vez más de sus obligaciones con su labor en el campo, radica, debido a la precisión de cada una de sus piezas, en la lentitud y la demora del proceso: "este proceso de perfeccionamiento sale adelante con tanta lentitud, que apenas se puede reconocer un avance de un año para el otro" $" 75$. Asimismo, al basarse en el estudio minucioso de diversas fuentes, y en los nuevos descubrimientos provenientes de investigaciones arqueológicas e históricas, el trabajo debe ser expuesto a constantes modificaciones. Garrard, año tras año, se enredó en su obra de bricolaje, en un redil sin calefacción, según sus vecinos y familiares en un proyecto "sin sentido y sin utilidad" al tiempo "que dejaba de labrar los campos y de procurar el cobro de las subvenciones que le correspondían" La demora y el arduo trabajo no utilitarista son para Garrard parte del sentido que escapa a las gramáticas económicas del capitalismo tardío. En una ocasión, uno de los tantos visitantes que con el tiempo han acudido a esa región campestre para admirar el portento en construcción, un evangelista americano, le consultó a Alee si el concepto que tenía del templo le había 
sido dado por revelación, a lo que este respondió: "If it had been divine revelation, I said to him, why would I have had to make alternations as I went along? No, it's just research really and work, endlees hours of work" "77. Un trabajo aparentemente improductivo, cuyos frutos no son acumulables o consumibles; trabajo que requiere de una técnica que contempla lo otro, al templo, y se nutre del conocimiento de una comunidad de sujetos. Una técnica que es también mnemotécnica, pues está atravesada por el ejercicio del recuerdo, por la reconstrucción de un pasado específico, y en esa preocupación busca y pone en juego distintos archivos de la memoria. Fuentes historiográficas, excavaciones arqueológicas, exégesis de textos sagrados, etc. Archivos que se actualizan y reviven en el proceso del gran archivista que es Garrard, que dejan de ser letras muertas para ser signos vivos en el presente ${ }^{78}$.

No otra cosa hace el paseante solitario con la multiplicidad de historias, recuerdos, sueños, impresiones, textos y fotografías que co-habitan y cobran vitalidad a través del dispositivo narrativo. El escritor con su memoria e imaginación asociativa como el gran dispositivo técnico que capta y deja registro de las imágenes del mundo en el tiempo. Este dispositivo técnico particularmente melancólico, opera por deflexión de las luces cegadoras del universo 24/7 propio del capitalismo tardío. Este fenómeno de deflexión, apunta Cadava, es esencial para la emergencia de cualquier imagen. "De hecho, la luz puede dar lugar a una imagen sólo cuando su camino está bloqueado, cuando resulta desviada de su curso (...) para ser revelada la luz debe ser interrumpida"79. La luminosidad del mundo, su trayecto inercial, imparable, debe ser interrumpido para hacernos una idea de lo que ella misma hace o deshace (crea o destruye). Y de esa imagen, si se logra ajustar y precisar la técnica o complejizar el soporte contra el que choca la luz, pueden revelarse las sombras y el espectro completo.

\section{Referencias}

AGAMBEN, Giorgio. Estancias. La palabra y el fantasma en la cultura occidental. Traducción Tomás Segovia. Buenos Aires: Editora Nacional Madrid, 2002.

BENJAMIN, Walter. "Sobre el concepto de historia". Traducción M. Reyes Mate. In: REYES MATE, M. Medianoche en la historia. Consideraciones a las tesis de Walter Benjamin "Sobre el concepto de historia". Madrid: Trotta, 2009.

CADAVA, Eduardo. Trazos de luz: Tesis sobre la fotografía de la bistoria. Traducción Paula Cortés Rocca. Chile: Palinodia, 2014.
72. Ibídem, p. 219.

73. Ibídem, p. 221.

74. Ibídem, p. 256.

75. Ibídem, p. 258.

76. Ibídem, p. 259.

77. Ibídem, p. 270. "Si hubiera sido revelación divina, le dije, ¿por qué habría tenido que hacer modificaciones como las que hice hasta ahora? No, es solo investigación y verdadero trabajo, horas interminables de trabajo." (La traducción es nuestra).

78. Sobre la cuestión del archivo y su relación con la memoria ver Mal de archivo de Jacques Derrida.

79. CADAVA, E. Trazos de lur: Tesis sobre la fotografía de la historia, 2014, p. 192. 
DERRIDA, Jacques. Mal de archivo. Traducción Farancisco Vidarte Fernández. Madrid: Trotta, 1997.

HABERMAS, Jurgen. El discurso filosófico de la modernidad. Traducción Manuel Jiménez Redondo. Buenos Aires: Katz, 2010.

HUYSSEN, Andreas. "Rewritings and New Beginnings: W. G. Sebald and the Literature on the Air War". In: Present

Pasts Urban Palimpsests and the Politics of Memory. Stanford:

Stanford University Press, 2003, p. 138-157.

HUTCHINSON, Ben. "Marinheiro ou camponês? Algumas reflexões sobre as leituras de Sebald do ensaio 'O narrador' de Walter Benjamin”. Tradução Cilene Rohr e Fabrício Coelho. Cadernos Benjaminianos. V. 12, 2016, p. 85-107. Disponível em: <http://www.periodicos.letras.ufmg.br/index.php/ cadernosbenjaminianos/article/view/11548/9975>.

KUFFER, Paula. "Representación, melancolía y resistencia: el materialismo espectral de W. G. Sebald”. Boletín de Estética. Año XI - Verano 2014-2015/No 30, p. 5-39.

MACIEL PEREIRA, Gerciano. "Algumas Reflexões sobre W. G. Sebald à Luz de Walter Benjamin”. Cadernos Benjaminianos. N. 3, jun. 2011, p.71-86. Disponível em: <http://www. periodicos.letras.ufmg.br/index.php/cadernosbenjaminianos/ article/view/5326>.

REYES MATE, Manuel. Medianoche en la historia. Comentarios a las Tesis de Walter Benjamin "Sobre el concepto de historia". Madrid: Trotta, 2009.

SEBALD, W.G. Los anillos de Saturno. Traducción Carmen Gómez y Georg Pilcher. Buenos Aires: Editorial Nacional Madrid, 2002.

- Sobre la historia natural de la destrucción. Traducción Miguel Sáenz. Barcelona: Anagrama, 2003. . Campo Santo. Traducción Miguel Sáenz. Barcelona: Anagrama, 2007. El paseante solitario. En recuerdo de Robert Walser. Traducción Miguel Sáenz. España: Siruela, 2008.

THIEBAUT, Carlos. "El relato del daño como historia natural: a propósito de W. G. Sebald”. Boletín de Estética. Año XI, primavera 2014, No 29. p. 5-91.

WEBER, Samuel. "Experiencia". Traducción María Belforte

Submissão: $11 / 05 / 2017$ Aceite: $27 / 06 / 2017$ y Miguel Vedda. In: OPITZ, Michael \& WISIZLA, Ermudt (Comp.) Conceptos de Walter Benjamin. Buenos Aires: Las Cuarenta, 2014. 